\title{
Biochemical effects of fipronil and its metabolites on lipid peroxidation and enzymatic antioxidant defense in tadpoles (Eupemphix nattereri: Leiuperidae)
}

\author{
Hortênsia S. Gripp ${ }^{\mathrm{a}}$, Juliane S. Freitas ${ }^{\mathrm{a}}$, Eduardo A. Almeida ${ }^{\mathrm{a}, \mathrm{b}}$, Márcia C. Bisinoti ${ }^{\mathrm{a}}$, \\ Altair B. Moreira, ${ }^{\mathrm{a}, *}$ \\ a Instituto de Biociências, Letras e Ciências Exatas, UNESP, Univ Estadual Paulista, Campus São José do Rio Preto, Departamento de Química e Ciências \\ Ambientais, Laboratório de Estudos em Ciências Ambientais, Cristóvão Colombo, 2265, São José do Rio Preto, São Paulo State 15054-000, Brazil \\ b Departamento de Ciências Naturais, Fundação Universidade Regional de Blumenau, Rua Antônio da Veiga, 140 - Itoupava Seca, 89030-903 Blumenau, \\ SC, Brazil
}

\section{A R T I C L E I N F O}

Keywords:

Amphibians

Pesticides

Fipronil

Toxicity

Oxidative stress

\begin{abstract}
A B S T R A C T
Amphibians are very sensitive to environmental change and pollution because they have both aquatic and terrestrial life cycle stages and high skin permeability. Particularly during the larval stages, when these animals are restricted to small, transient ponds, exposure to high concentrations of pesticides is inevitable in agricultural areas. Given that pesticide application increases during the summer, which coincides with the reproductive season and the occurrence of most neotropical tadpoles in their natural environment, strong indications exist that tadpoles are developing in contaminated ponds. Fipronil is one of the primary insecticides used in sugarcane cultivation in Brazil, and little is known about its toxic effects on non-target organisms such as tadpoles. The purpose of this study was to evaluate the effects of fipronil and its metabolites on oxidative stress in Eupemphix nattereri tadpoles after exposure in water and sediment at concentrations of 35, 120 and $180 \mu \mathrm{g} \mathrm{kg}^{-1}$. We assessed the activities of the antioxidant enzymes glutathione S-transferase (GST), glucose 6phosphate dehydrogenase (G6PDH) and catalase (CAT) and lipid peroxidation (malondialdehyde, MDA). The results showed that fipronil has an inherent capacity to cause oxidative stress in tadpoles, as evidenced by a decrease in CAT activity and an increase in lipid peroxidation levels at all concentrations tested. Fipronil sulfone also produced elevated MDA levels at two of the tested concentrations and increased G6PDH activity in tadpoles exposed to the highest concentration of this metabolite but did not affect MDA levels. Our data showed that fipronil and its degradation products promoted oxidative stress in Eupemphix nattereri tadpoles exposed to environmentally relevant concentrations and could lead to a decrease in the long-term physiological performance of these animals, leading to detrimental effects at the population level.
\end{abstract}

\section{Introduction}

The intensification of agricultural activity in Brazil has caused extensive environmental impacts on many ecosystems, especially due to intensive pesticide use. Brazil is the largest consumer of pesticides in the world, with São Paulo being responsible for approximately $20 \%$ of the national consumption. In northwest São Paulo, the principal crop is sugarcane, and the cultivated area has increased in recent years (UNICA, 2015). Sugarcane cultivation requires a large amount of pesticides, especially the herbicides diuron, tebuthiuron and glyphosate and the insecticides carbofuran and fipronil (Bicalho et al., 2010; Peret et al., 2010). In Brazil and other tropical regions of the world, application of these pesticides is generally intensified during the rainy season, which coincides with the reproductive period of most amphibian species. Because many amphibians are distributed in areas common to agriculture practice, there is a great concern that many species are being affected by exposure to local pesticides.

The phenylpyrazole fipronil (5-amino-1-[2,6-dichloro-4-(trifluoromethyl)phenyl]-4-(trifluoromethylsulfonyl)pyrazole-3-carbonitrile) is among the most commonly used insecticides, which acts directly on the $\gamma$-aminobutyric acid (GABA) chloride channels in insects to disrupt neuronal signalling (Gunasekara and Troung, 2007). GABA antagonists such as fipronil are known to cause hyperactivity, convulsions and death in fish (Beggel et al., 2012). In addition, recent evidence suggests

\footnotetext{
* Corresponding author

E-mail address: altair@ibilce.unesp.br (A.B. Moreira).
} 
that fipronil also induces reactive oxygen species (ROS) production in cells, which can lead to increased lipid peroxidation and oxidative stress (Ki et al., 2012; Margarido et al., 2013; Möhler et al., 2004).

Under the aerobic conditions and sandy soils that characterize regions of sugarcane cultivation, fipronil has a half-life of 122-128 days. According to the Groundwater Ubiquity Score (GUS) index, fipronil and its degradation products have a low affinity for water, moderate mobility in soil and a sorption coefficient (Koc) of 803. Fipronil sulfone and fipronil sulfide also have low mobility and Koc values of 2511 and 3981, respectively. Fipronil has high affinity for natural organic matter present in water and sediments and is more susceptible to photodegradation than hydrolysis, except under alkaline conditions (Gunasekara and Troung, 2007; Gustafson, 1989).

In general, pesticides may be transported by drift, precipitation and runoff and may be found in different environmental matrices such as soil, surface water, and sediment, thus affecting various non-target organisms (Edwards, 1993; Hoerger et al., 2014; LeNoir et al., 1999; Moreira et al., 2010; Peret et al., 2010; Rand et al., 1995). Once in the environment, pesticides can be degraded, generating by-products that can be more or less toxic than the original compound (Cheyns et al., 2010; Gunasekara and Troung, 2007; Katagi, 2004; Muneer et al., 1999). Fipronil degradation gives rise to several products, especially fipronil sulfide and fipronil sulfone, which are generated by reduction and oxidation reactions, respectively. The concentrations of fipronil, fipronil sulfone and fipronil sulfide in the soil of São José do Rio Preto, São Paulo, Brazil were recently shown to range between 35 and $180 \mu \mathrm{g} \mathrm{kg}^{-1}$ (de Toffoli et al., 2015). These soils undergo flooding during the rainy season, forming temporary ponds that are used by anurans for reproduction. Due to their proximity to the cultivation areas, fipronil concentrations in these ponds can be higher than those commonly found in most permanent aquatic environments, such as rivers and lakes, thereby posing a substantial risk for local anuran species. However, to our knowledge, data regarding fipronil concentrations in small temporary ponds formed close to agriculture areas are not described in the scientific literature.

Amphibians are known to be more sensitive to pesticide contamination during the larval stage than as adults because tadpoles are strictly aquatic and have higher skin permeability (Yan et al., 2008). Once in water, fipronil rapidly partitions between the water column and the sediment (Maul et al., 2008; Tingle et al., 2003), posing a risk to benthic organisms such as Eupemphix nattereri tadpoles, which use the sediment and organic matter as a food source. However, studies on how fipronil affects tadpoles are still limited. Many studies have found that exposure of tadpoles to pesticides such as atrazine, glyphosate, quinclorac and fipronil in laboratory assays may alter the antioxidant response and may trigger oxidative stress (e.g., Dornelles and Oliveira, 2016; Margarido et al., 2013). Margarido and collaborators showed that fipronil impairs the antioxidant defense system in Scinax fuscovarius tadpoles, increasing their susceptibility to oxidative stress. However, no studies have investigated the effects of fipronil metabolites. Additionally, the study by Margarido et al. (2013) considered only fipronil dissolved directly in water and used a commercial formulation (Regent ${ }^{\circledR}$ 800WG). Due to the low water solubility of fipronil, it is possible that its association with aquatic sediment contributes more to its toxicity, especially towards benthic species that feed by foraging through the sediment. Therefore, the present study aimed to evaluate the effect of fipronil and its metabolites, fipronil sulfone and fipronil sulfide, at different environmental concentrations found in soils near sugarcane crops. To monitor oxidative stress, we measured malondialdehyde (MDA) levels to indicate lipid peroxidation and the activities of the antioxidant enzymes catalase (CAT), glucose-6-phosphate dehydrogenase (G6PDH) and glutathione S-transferase (GST, also a phase II biotransformation enzyme) in Eupemphix nattereri tadpoles, one of the most common benthic tadpole species found in the northwest region of São Paulo State, Brazil.

\section{Material and methods}

\subsection{Test organisms}

Spawn of the anuran Eupemphix nattereri (Leiuperidae) were collected from temporary ponds in the São José do Rio Preto region in northwest São Paulo State, Brazil (20 47' 07.05"S, 49 02' 42.09" $\mathrm{W})$, during the rainy season (November-February). The larvae were kept in the laboratory under ideal temperature $\left(28^{\circ} \mathrm{C}\right), \mathrm{pH}(7.5-8.0)$ and oxygen $(\sim 5 \mathrm{mg} / \mathrm{L})$ conditions until they reached stages $29-33$ $(0.081 \pm 0.018 \mathrm{~g})$ just before the development of legs (Gosner, 1960). The animals were collected under license n.18573-1, authorized by the Brazilian Institute of Environment and Renewable Natural Resources (IBAMA), and this work was approved by the Ethics Committee on Animal Use in Research of the São Paulo State University (CEUAIBILCE/UNESP nº 086/2013).

\subsection{Preparation of fipronil and its metabolites in the water and the sediment}

Prior to exposure, the concentrations of fipronil and its metabolites in the water and the sediment were measured in aquariums in the absence of tadpoles to better understand the dispersion and availability of the compounds in the sediment and water. For this experiment, fipronil, fipronil sulfide and fipronil sulfone were tested at three concentrations: 35,120 and $180 \mu \mathrm{g} \mathrm{kg}^{-1}$. For the preparation of the experimental concentrations (35, 120 and $180 \mu \mathrm{g} \mathrm{kg}^{-1}$ ), 7, 24 and $36 \mu \mathrm{g}$ of each compound (fipronil, fipronil sulfide or fipronil sulfone), from stock solutions $\left(72 \mathrm{mg} \mathrm{L}^{-1}\right)$ were diluted in acetone and then separately added to $200 \mathrm{~g}$ of soil. Water $(1 \mathrm{~L})$ was added to aquariums only after the acetone had evaporated. The soil was collected from nonagricultural areas of Sao Jose do Rio Preto, SP-Brazil, cleaned and washed twice with water and acetone, and used in the experiments only after the solvents had totally evaporated. No traces of fipronil or any of its metabolites were detected in the soil samples after the clean-up procedure. The concentrations of fipronil and the metabolites that were added to the soil were selected based on a recent study that found similar concentrations in soils close to agricultural areas in the region of São José do Rio Preto, Brazil (de Toffoli et al., 2015). The aquariums were agitated to disperse the compounds into the aqueous phase and placed on a horizontal surface to allow the soil to settle. Control aquariums with the solvent alone were also prepared using the same procedure for comparison. After $24 \mathrm{~h}$, when the soil fraction had completely settled, water and soil were collected for chemical analysis. Chemical analysis of soil and water were also performed after 7 days after experimental exposure to the compounds in all aquariums containing tadpoles.

\subsection{Chemical analysis}

Fipronil and its metabolites were extracted from the water and sediment samples according to the method described by de Toffoli et al. (2015), which involves solid-phase extraction (SPE) on C18 cartridges (Supelco Analytical, Bellefonte, Pennsylvania, USA) for the water samples and liquid-liquid extraction (acetone/dichloromethane) for the sediment. To monitor the recovery rate, all water and sediment samples were spiked with the surrogate diazinon d-10 $\left(40.0 \mu \mathrm{g} \mathrm{L}^{-1}\right)$. Deuterated d-10 phenanthrene $(1.0 \mathrm{mg} / \mathrm{L})$ was also used as an internal standard, before separation on C18 SPE cartridges. The cartridges were conditioned with $3.0 \mathrm{~mL}$ of a 3: 1 solution of hexane/isopropanol (Sigma-Aldrich, Germany) followed by $0.5 \mathrm{~mL}$ of methanol (Merck SupraSolv $^{\circledast}$, Germany) and finally $1.0 \mathrm{~mL}$ of ultrapure water. With the aid of a manifold system (Agilent Technologies, USA), $400.0 \mathrm{~mL}$ of sample that had been pre-filtered through $0.7-\mu \mathrm{m}$ glass fibre (Sartorius Stedim Biotech, Germany) was percolated through the cartridge and then extracted, and analytes were eluted with $3.0 \mathrm{~mL}$ of ethyl acetate 
(Sigma-Aldrich, Mexico). The eluate was dried under commercial nitrogen in a drying block (SL - 1625 Solab, Brazil) and resuspended in a total volume of $1000 \mu \mathrm{L}(800 \mu \mathrm{L}$ of ethyl acetate and $200 \mu \mathrm{L}$ of internal standard). The sediment samples were extracted via sonication. Dried sediment $(20.0 \mathrm{~g})$ and anhydrous sodium sulfate $(10.0 \mathrm{~g})$ (Sigma-Aldrich, Germany) were dissolved in $50.0 \mathrm{~mL}$ of $1: 1$ acetone/ dichloromethane (Macron Fine Chemicals, USA), and the mixture was sonicated for $15 \mathrm{~min}$ (USC-1600A, Unique, Brazil). The supernatant was transferred to vials for subsequent filtration through $0.7-\mu \mathrm{m}$ glass fibre, dried in a gas drying block under commercial nitrogen and resuspended in a total volume of $1000 \mu \mathrm{L}(800 \mu \mathrm{L}$ of ethyl acetate and $200 \mu \mathrm{L}$ of internal standard). Fipronil and its derivatives were then quantified on a gas chromatograph, model 7890A, coupled to mass spectrometer, model 5975C (Agilent Technologies, Santa Clara, California, USA) (GC-MS), using an HP-5MS column (5\% phenyl 95\% polydimethylsiloxane, $30 \mathrm{~m} \times 0.25 \mathrm{~mm} \times 0.25 \mu \mathrm{m}$ ) from Agilent Technologies, USA, following laboratory QA/QC protocols.

\subsection{Exposure of tadpoles to fipronil and its metabolites}

E. nattereri tadpoles were separately exposed to 35,120 and $180 \mu \mathrm{g} \mathrm{kg}^{-1}$ of the insecticide fipronil $\left(\mathrm{C}_{12} \mathrm{H}_{4} \mathrm{Cl}_{2} \mathrm{~F}_{6} \mathrm{~N}_{4} \mathrm{OS}\right)$ or its metabolites fipronil sulfide $\left(\mathrm{C}_{12} \mathrm{H}_{4} \mathrm{Cl}_{2} \mathrm{~F}_{6} \mathrm{~N}_{4} \mathrm{~S}\right)$ and fipronil sulfone $\left(\mathrm{C}_{12} \mathrm{H}_{4} \mathrm{Cl}_{2} \mathrm{~F}_{6} \mathrm{~N}_{4} \mathrm{O}_{2} \mathrm{~S}\right)$. For each treatment, amounts corresponding to the studied concentrations of the compounds (7, 24 and $36 \mu \mathrm{g})$ were added to aquariums containing $200 \mathrm{~g}$ of soil and $1.0 \mathrm{~L}$ of dechlorinated water, exactly as described in item 2.2. Tadpoles were exposed to each concentration at constant temperature of $26^{\circ} \mathrm{C}$ for 7 days. Each experimental group consisted of four replicates containing eight tadpoles in each aquarium ( $\mathrm{n}=4$ replicates; 32 pseudo-replicates), totalling 384 tadpoles. Control groups also received the same volume of acetone to avoid ambiguous interpretation of the results due to possible solvent effects, and water was added to the aquariums only after total evaporation of the solvent. The aquariums were maintained under constant aeration, $\mathrm{pH}(8.0 \pm 0.3)$ and photoperiod (12-h lightdark cycle) during the experiment. The water was not changed during the experiment, but excrement and food scraps were removed every two days, when the tadpoles were fed. The levels of ammonia and dissolved oxygen in the water were measured at the end of the experiment, and tadpoles were collected, immediately frozen in liquid nitrogen and subsequently stored at $-80{ }^{\circ} \mathrm{C}$.

\subsection{Preparation of tadpole protein extracts for biochemical analyses}

For enzymatic analysis, the tadpoles were individually and thoroughly homogenized (1:4, w-v) in Tris- $\mathrm{HCl}$ buffer, $\mathrm{pH} 7.5$, containing $0.5 \mathrm{mM}$ phenylmethylsulfonyl fluoride (PMSF, Sigma-Aldrich, China) as a protease inhibitor, and then centrifuged $(9,000 \mathrm{~g})$ at $3.0^{\circ} \mathrm{C}$ for $20 \mathrm{~min}$. The supernatant was then centrifuged again at $50,000 \mathrm{~g}$ and $3.0^{\circ} \mathrm{C}$ for $60 \mathrm{~min}$. The resulting supernatant was collected and used to measure GST, CAT and G6PDH activity.

Lipid peroxidation was assessed by measuring MDA levels. Animals $(\sim 100 \mathrm{mg})$ were homogenized at a 1:3 (w:v) ratio in $0.1 \mathrm{M}$ Tris- $\mathrm{HCl}$ buffer, pH 8.0. After homogenization, $300 \mu \mathrm{L}$ of thiobarbituric acid (TBA, Sigma-Aldrich, Germany) diluted in $0.4 \% \mathrm{HCl}$ was added to the sample. The mixture was heated at $90{ }^{\circ} \mathrm{C}$ for $40 \mathrm{~min}$, and the reaction products were extracted with $1.0 \mathrm{~mL}$ of $n$-butanol (Sigma-Aldrich, USA). The $n$-butanol-extracted fraction $(50 \mu \mathrm{L})$ was injected into a High-Performance Liquid Chromatography (HPLC) system.

\subsection{Biochemical analysis}

GST activity was measured following the method of Keen et al. (1976), adapted for a microplate reader (Victor-X3, Perkin Elmer, Singapore). The reaction system contained $0.2 \mathrm{M}$ phosphate buffer, $\mathrm{pH}$ 6.5, $1 \mathrm{mM}$ 1-chloro-2,4-dinitrobenzene (CNDB, Sigma-Aldrich,
Germany), and $1 \mathrm{mM}$ reduced Glutathione (GSH, Sigma-Aldrich, Japan), and the sample was monitored for $1 \mathrm{~min}$ at $340 \mathrm{~nm}$. G6PDH activity was also measured in a microplate reader following the method of Glock and McLean (1953) by measuring the reduction of NADP to $\mathrm{NADPH}$ at $340 \mathrm{~nm}$, with glucose-6-phosphate as the substrate. CAT activity was measured using the spectrophotometric method described by Beutler (1975), which quantifies the rate of hydrogen peroxide decomposition by the enzyme by measuring the decrease in absorbance at $240 \mathrm{~nm}$ using a spectrophotometer (Thermo Evolution 300, Madison, WI USA). Protein concentrations were determined using the Bradford method (1976) adapted for a microplate reader at a wavelength of $595 \mathrm{~nm}$. Bovine serum albumin served as the standard.

MDA levels were determined as described by Almeida (2003) using HPLC (ESA, Chelmsford, Massachusetts, USA) coupled to a UV-vis detector (526, ESA, Chelmsford, Massachusetts, USA) to analyse the product formed by the reaction of MDA and TBA. A Shimadzu C18 column $(150 \times 4.6 \mathrm{~mm}, 5 \mu \mathrm{m})$ was used for the analysis, with a mobile phase of $50 \mathrm{mM}$ potassium phosphate $(\mathrm{pH} 7.0)$ in $40 \%$ methanol at a flow rate of $1.0 \mathrm{~mL} / \mathrm{min}$.

\subsection{Statistical analysis}

Statistical analyses were performed using R software version 2.11.1 (stats package) (R Development Core Team, 2010). Differences in the activities of GST, G6PDH and CAT and MDA levels were evaluated in all groups after exposure to fipronil and its metabolites. Outliers were assessed, and the normality and homogeneity of data were verified by the Shapiro-Wilk and Levene's test, respectively. For parametric data, significant differences were assessed using one-way ANOVA followed by Tukey's post hoc test, and nonparametric data were evaluated using the Kruskal-Wallis test followed by an additional multiple comparison test of the means. $\mathrm{P}$ values $<0.05$ were considered statistically significant.

\section{Results}

\subsection{Analysis of water and sediment}

After $24 \mathrm{~h}$ (aquariums without tadpoles), the lower concentration of fipronil $\left(35 \mu \mathrm{g} \mathrm{kg}^{-1}\right)$ was found in a greater proportion in the water than in the soil. The same occurred for all concentrations of the metabolites of fipronil sulfone and fipronil sulfide. Concentrations of fipronil and its metabolites in sediment and water after $24 \mathrm{~h}$ are shown in Fig. 1. After 7 days of exposure, we found that fipronil, fipronil sulfone and fipronil sulfide were all preferentially deposited in the sediment in all aquariums containing tadpoles. For fipronil, fipronil sulfone and fipronil sulfide, after 7 days, the percentages of analyte adsorbed in the sediment ranged from $58 \%$ to $77 \%, 72 \%$ to $85 \%$, and $95 \%$ to $98 \%$, respectively, of the amount initially added to the aquariums.

\subsection{Biochemical analysis}

All of the tadpoles survived in all of the treatments, indicating that at the concentrations studied, fipronil and its metabolites are not lethal to tadpoles after 7 days of exposure. GST activity was unchanged in tadpoles exposed to fipronil and its metabolites (Fig. 2A). Compared with the control group, G6PDH activity was higher only in tadpoles exposed to the highest fipronil sulfide concentration ( $\mathrm{P}=0.02)$, but no significant changes were observed for the other compounds (Fig. 2B). However, tadpoles exposed to fipronil sulfone at $35 \mathrm{\mu g} \mathrm{kg}^{-1}$ had higher G6PDH activity than those exposed to fipronil at the same concentration. CAT activity was unaltered in tadpoles exposed to fipronil and its metabolites at the lower concentrations $(\mathrm{P}=0.36)$. On the other hand, decreased CAT activity was detected in tadpoles exposed to $120 \mu \mathrm{g} \mathrm{k}^{-1}$ of fipronil $(\mathrm{P}=0.01)$, and increased CAT activity was observed at the 


\section{Hours}
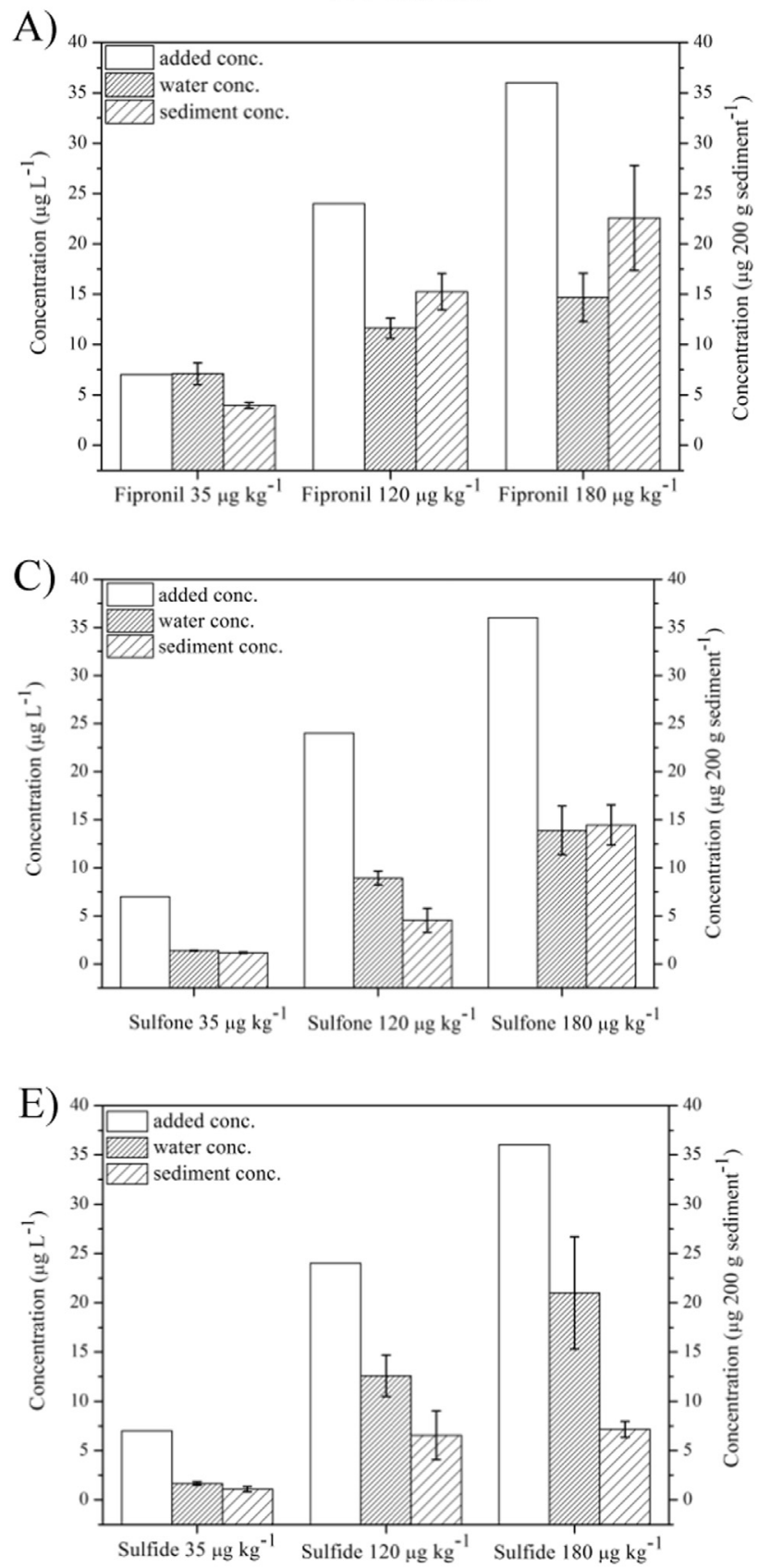

7 Days
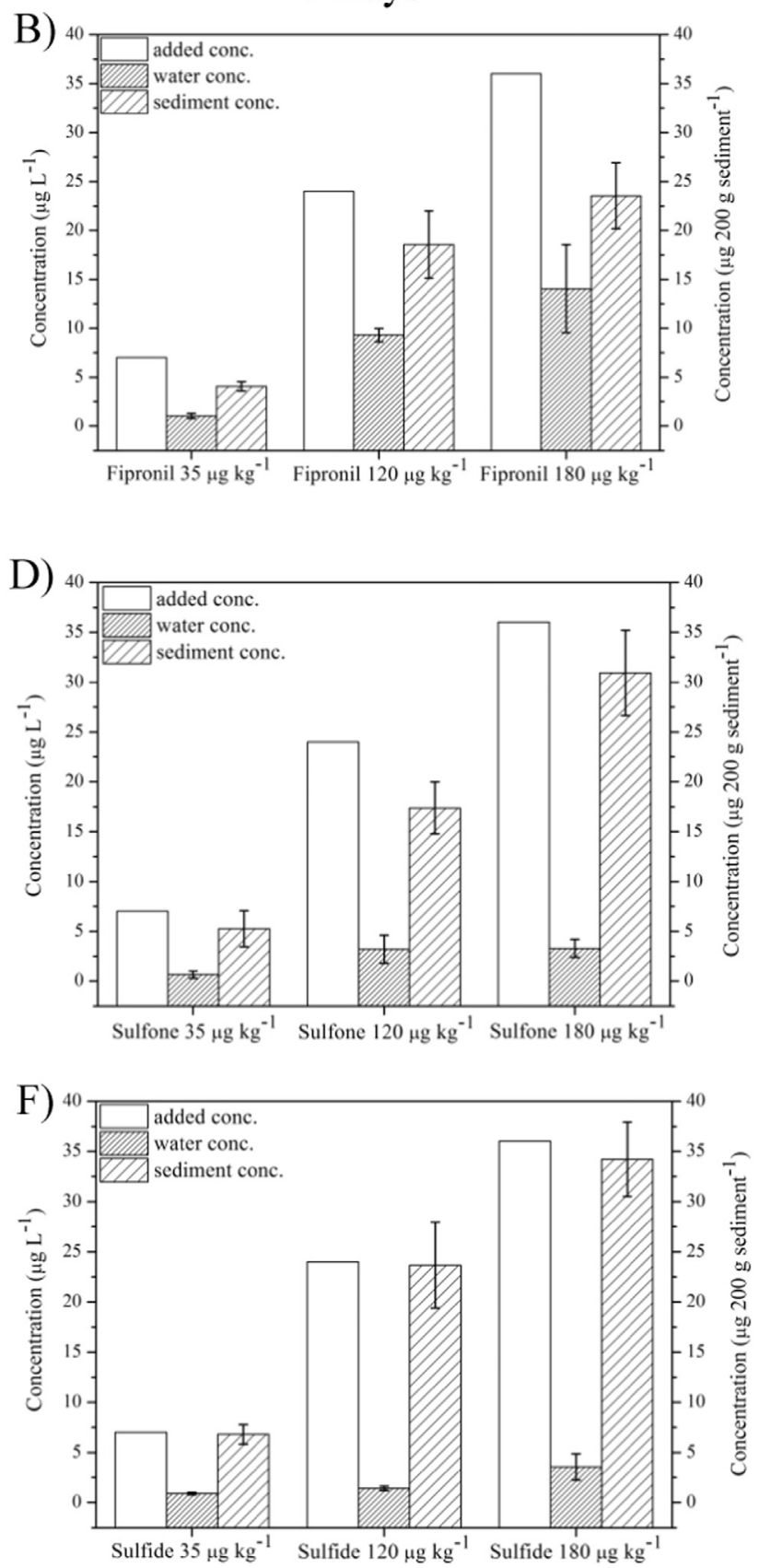

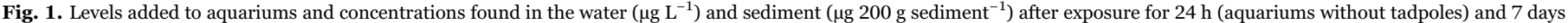

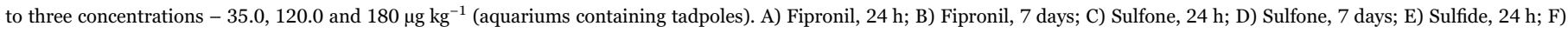
Sulfide, 7 days.

highest concentration of fipronil sulfide ( $\mathrm{P}=0.02)$ (Fig. 2C).

Lipid peroxidation was increased in tadpoles exposed to fipronil at all concentrations tested $(\mathrm{P}<0.001)$ compared to the control group (Fig. 3). For tadpoles exposed to fipronil sulfone, MDA levels increased upon exposure to $35.0 \mu \mathrm{g} \mathrm{kg}^{-1}(\mathrm{P}<0.001)$ and $180.0 \mu \mathrm{g} \mathrm{kg}^{-1}(\mathrm{P}=0.03)$ but to a lesser extent than in the fipronil group. Tadpoles exposed to fipronil sulfide showed no alterations in MDA levels at any of the concentrations studied.

\section{Discussion}

Although most pesticides have selective toxicity against specific organisms, some can also be harmful to non-target organisms, depending on the concentration and route of exposure (Woo et al.,
2009). Pesticides applied to soils for agricultural practices can exert toxic effects on tadpoles during the rainy seasons because the intense rain can form temporary ponds that can be used by anurans for reproduction and spawning. Fipronil has a relatively low solubility in water, although adjuvant compounds present in commercial formulations can increase its water solubility. However, due to its low solubility in water, fipronil is expected to be associated with the sediment in water environments, and its effects could be more pronounced for benthic organisms that inhabit and feed within sediments, such as $E$. nattereri tadpoles. The chemical analysis of water and sediment conducted in this study after $24 \mathrm{~h}$ showed that although the compounds present moderate lipophilicity, the adsorption of these compounds in the sediment occurs slowly because after $24 \mathrm{~h}$, the compounds were preferentially present in water, with the exception of 

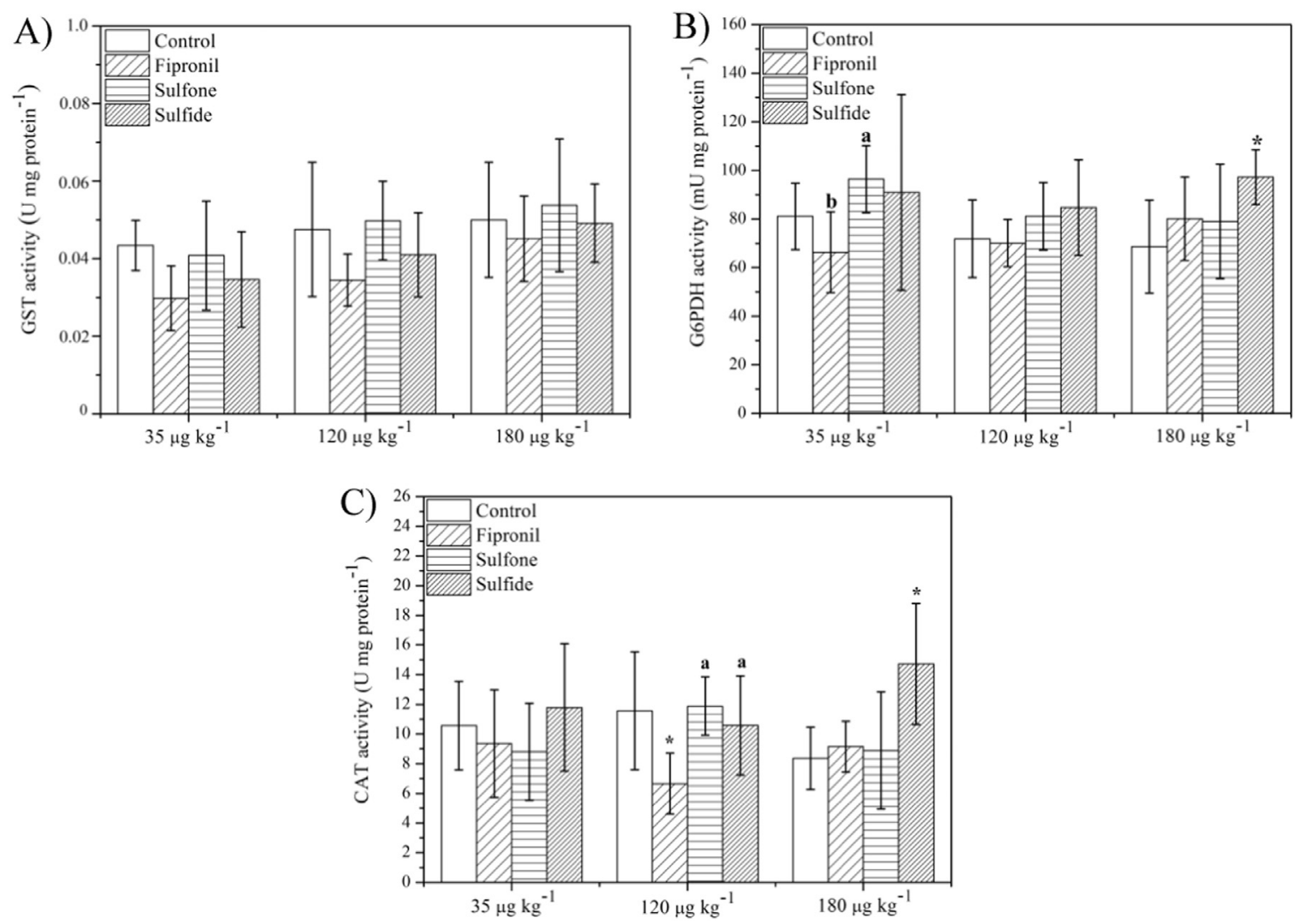

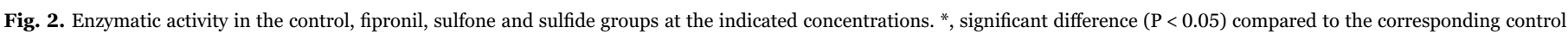

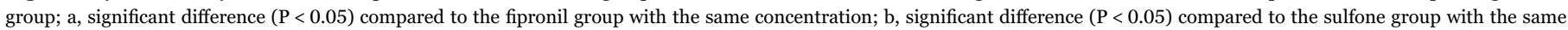
concentration. A) GST activity; B) G6PDH activity; C) CAT activity.

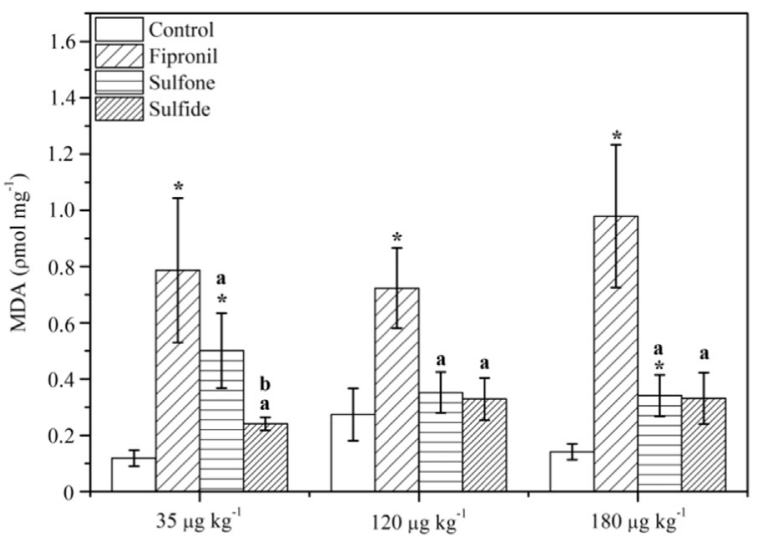

Fig. 3. MDA concentrations ( $\mathrm{pmol} \mathrm{mg}^{-1}$ ) in the control, fipronil, sulfone and sulfide groups at the indicated concentrations. ${ }^{*}$, significant difference $(\mathrm{P}<0.05)$ compared to the corresponding control group; a, significant difference $(\mathrm{P}<0.05)$ compared to the fipronil group with the same concentration; $b$, significant difference $(\mathrm{P}<0.05)$ compared to the sulfone group with the same concentration.

fipronil at the lower concentration $\left(35 \mu \mathrm{g} \mathrm{kg}^{-1}\right)$. Water and sediment analyses performed after 7 days showed that all compounds were predominantly found in the sediment and were more available for benthic organisms, confirming the high lipophilicity of these compounds.

The results presented in this study showed that although fipronil and its metabolites altered the activity of some antioxidant enzymes, these alterations were variable, and the enzymes did not exhibit dosedependent changes in response to fipronil and its metabolites in $E$. nattereri tadpoles. Nevertheless, these alterations in antioxidant enzymes suggest a modulation in response to increased ROS generation due to pesticide exposure. Increased levels of MDA caused by exposure to fipronil and fipronil sulfone also indicate an oxidative stress condition resulting from exposure of the tadpoles to these contaminants. It has been shown that stress conditions eventually cause an increase in ROS production in aquatic organisms, suggesting that changes in antioxidant enzyme activities are associated with the adaptation of these organisms to environmental changes (Lushchak, 2011; Tomanek, 2014).

CAT and G6PDH activity increased in organisms exposed to the higher concentration of the sulfide metabolite, which could be related to the lack of increased MDA levels in this group. CAT activity was also increased in animals exposed to the intermediate concentration $\left(120 \mu \mathrm{g} \mathrm{kg}^{-1}\right)$ of fipronil sulfide. However, a decrease in CAT activity was observed in tadpoles exposed to $120 \mu \mathrm{g} \mathrm{kg}^{-1}$ of fipronil, indicating a possible inhibitory effect of fipronil on this enzyme and a consequent increase in the susceptibility of the tadpoles to oxidative stress, which could be related to the high lipid peroxidation level in this group. Previous studies have shown that CAT activity may be inhibited in animals exposed to different pesticides (Margarido et al., 2013; Peltzer et al., 2013; Sun et al., 2014), including the insecticide fipronil, which inhibited CAT activity in the fish Cyprinus carpio after exposure to $0.65 \mathrm{mg} \mathrm{L}^{-1}$ after 7, 30 and 40 days (Clasen et al., 2012). In contrast, Scinax fuscovarious tadpoles exposed to 5, 20 and $100 \mu \mathrm{g} \mathrm{L}^{-1}$ of a commercial formulation of fipronil (Regent 800WG) exhibited no alterations in CAT activity after 5, 10 and 14 days of exposure (Margarido et al., 2013). These data indicate that CAT may be altered by fipronil in different ways in different organisms, and also that fipronil metabolites are able to alter the activity of this enzyme, causing the animals to be more vulnerable to deleterious effects caused ROS.

The enzyme G6PDH was increased only in tadpoles exposed to the metabolite sulfide at higher concentration. Exposure to fipronil did not alter G6PDH activity at any concentrations. G6PDH is an important cytosolic enzyme that participates of the first step of the pentose 
phosphate pathway. It is an important source of NADPH and an important co-factor for antioxidant enzymes and numerous other biosynthetic reactions (Kletzien et al., 1994). A previous study with $S$. fuscovarious tadpoles also showed that fipronil did not alter the activity of G6PDH (Margarido et al., 2013). These results suggest that the metabolite fipronil sulfide may act by changing the G6PDH activity of tadpoles by a different pathway from that of the original compound, fipronil. Additionally, the increase in G6PDH observed in our study could also be a response to the increased demand of NADPH in the cells in an attempt to reduce the oxidant effects caused by the contaminant.

GST activity was unchanged by contaminants in this study. GSTs are a family of multifunctional dimeric enzymes involved in phase II reactions of biotransformation of several xenobiotics and also protect animals against oxidative damage because some isoforms have peroxidase activity. They are also responsible for the intracellular transport of endogenous and exogenous chemicals (Blanchette et al., 2007; Eaton and Bammler, 1999; Frova, 2006; Goto et al., 2009; Sheehan et al., 2001). The lack of variation in GST activity in tadpoles contrasts with previous findings by Margarido et al. (2013), in which a significant decrease in GST activity was observed in $S$. fuscovarius tadpoles exposed to the commercial formulation of fipronil (Regent ${ }^{\circledR} 800 \mathrm{WG}$ ). This discrepancy could be due to the commercial formulation of fipronil, which contains unknown adjuvant compounds that likely trigger different responses in tadpoles that are not triggered by the active ingredient, fipronil. In addition, the presence of adjuvants in the commercial formulation (Regent ${ }^{\circledR} 800 \mathrm{WG}$ ) could have increased the water solubility of fipronil and thus increased its bioavailability. Nevertheless, the lack of alteration of GST activity could also indicate that fipronil and its metabolites are not metabolized by this enzyme, and therefore, GST is not affected by these contaminants. In fact, Roques et al. (2012) demonstrated that rats treated with fipronil and fipronil sulfone presented an increase in the expression of CYP3A1, CYP2B2, glucuronosyltransferase and sulfotransferase transcripts, suggesting the involvement of these enzymes in fipronil and fipronil sulfone metabolism.

The lack of evident antioxidant responses in tadpoles exposed to fipronil and the sulfone metabolite may explain the higher susceptibility of these organisms to oxidative stress, as evidenced by increased MDA levels. All groups treated with fipronil exhibited increased levels of MDA at the concentrations studied. In contrast, fipronil sulfone and sulfide did not exacerbate oxidative stress at high concentrations, though the sulfone metabolite had an effect at the lowest concentration tested. In combination with the lack of response of the antioxidant enzymes in animals exposed to fipronil, the prominent increase in MDA levels induced by fipronil suggests that tadpoles exposed to the original compound may be more susceptible to lipid membrane damage than those exposed to the metabolites. Lipid peroxidation is considered a major negative effect of oxidative stress as a consequence of excessive ROS generation in cells. Cells employ various mechanisms to counteract oxidative stress and repair damaged macromolecules, and the primary defense is provided by enzymatic antioxidants (Ojha et al., 2011). Several studies have shown that MDA levels can be increased in aquatic organisms exposed to different pesticides such as organochlorines, organophosphates and carbamates, which makes MDA an important biomarker for different conditions of environmental stress (e.g., Slaninova et al., 2009; Uchendu et al., 2012). MDA levels have also been used in bioassays of amphibians to assess deleterious effects triggered by pesticide exposure. For example, Lithobates catesbeianus tadpoles exposed to atrazine, glyphosate and quinclorac exhibited an increase in MDA levels (Dornelles and Oliveira, 2014). Increased MDA levels in tadpoles exposed to fipronil in our study suggest that this compound increases ROS generation in the animal and that larval antioxidant defense systems are not sufficiently robust to protect against ROS increases after 7 days of fipronil exposure, leading these organisms to suffer the deleterious effects caused by lipid peroxidation.

Because amphibians are among the most sensitive vertebrates that can be used in ecotoxicity tests and are also the main group threatened by the overuse of agriculture pesticides, knowledge of the toxicity and physiological response to many pesticides evaluated by different bioassays is always valuable. In addition, the use of biomarkers such as antioxidant enzymes and lipid peroxidation is an important tool to assess the sensitivity of a species in its environment because the toxicity of and response to different compounds are species-specific. $E$. nattereri is an endemic Brazilian species, and our data have shown the potential of the insecticide fipronil to cause oxidative stress during the larval stage. These results imply that recent increases in the cultivation area for sugarcane can promote changes in the normal defense system used by these animals to survive in contaminated areas, potentially leading to a reduction in their adaptive response and to subsequent population decline.

In summary, our study showed how exposure to fipronil and its metabolites at environmentally relevant concentrations can impair the antioxidant system and establish oxidative stress in $E$. nattereri tadpoles. The variations of antioxidant enzymes may alter physiological performance during the larval development of amphibians in environments contaminated by fipronil because these enzymes are crucial pathways that protect the organisms against possible increases in ROS production and avoid oxidative stress. We also observed that exposure to the original fipronil compound increased MDA levels, suggesting that fipronil has an increased capacity to induce oxidative stress in $E$. nattereri tadpoles. Because the effects of fipronil metabolites were less pronounced at the concentrations studied, it is possible that fipronil degradation in the environment can decrease its toxicity. Nevertheless, additional studies are necessary to better address the toxicity of fipronil in comparison to its degradation metabolites, paying particular attention to the response of other key endpoints of tadpole development and health, such as hormonal changes, malformation, mortality and genotoxicity. These data are of great relevance for studies that monitor the effects of pesticides, such as the insecticide fipronil, on amphibian populations, especially neotropical species, which have very limited data in the literature.

\section{Acknowledgements}

The authors acknowledge support from FAPESP (Grants 2011/ 00574-1; 2013/07937-8; 2013/16948-3). We also appreciate the financial support scholarship from CAPES. E.A. Almeida is a recipient of a productivity fellowship by CNPq (307603/2014-8) .

\section{References}

Almeida, E.A., 2003. Avaliação de Variaç̃es Bioquímicas em Moluscos bivalves em Resposta ao Estresse Ambiente (Ph.D. thesis). Universidade de São Paulo - Instituto de Química, São Paulo, Brasil.

Beggel, S., Werner, I., Connon, R.E., Geist, J.P., 2012. Impacts of the phenylpyrazole insecticide fipronil on larval fish: time-series gene transcription responses in fathead minnow (Pimephales promelas) following short-term exposure. Sci. Total Environ. 426, 160-165. http://dx.doi.org/10.1016/j.scitotenv.2012.04.005.

Beutler, E., 1975. Red Cell Metabolism: A Manual of Biochemical Methods. Grune \& Straton, New York.

Bicalho, S.T.T., Langenbach, T., Rodrigues, R.R., Correia, F.V., Hagler, A.N., Matallo, M.B., Luchini, L.C., 2010. Herbicide distribution in soils of a riparian forest and neighboring sugar cane field. Geoderma 158, 392-397. http://dx.doi.org/10.1016/ j.geoderma.2010.06.008.

Blanchette, B., Feng, X., Singh, B.R., 2007. Marine glutathione S-transferases. Mar. Biotechnol. 9, 513-542. http://dx.doi.org/10.1007/s10126-007-9034-0.

Bradford, M.M., 1976. A rapid and sensitive method for the quantitation of microgram quantities of protein utilizing the principle of protein-dye binding. Anal. Biochem. 72, 248-254. http://dx.doi.org/10.1016/0003-2697(76)90527-3.

Cheyns, K., Mertens, J., Diels, J., Smolders, E., Springael, D., 2010. Monod kinetics rather than a first-order degradation model explains atrazine fate in soil minicolumns: implications for pesticide fate modelling. Environ. Pollut. 158, 1405-1411. http://dx.doi.org/10.1016/j.envpol.2009.12.041.

Clasen, B., Loro, V.L., Cattaneo, R., Moraes, B., Lópes, T., de Avila, L.A., Zanella, R., Reimche, G.B., Baldisserotto, B., 2012. Effects of the commercial formulation 
containing fipronil on the non-target organism Cyprinus carpio: implications for rice-fish cultivation. Ecotoxicol. Environ. Saf. 77, 45-51. http://dx.doi.org/10.1016/ j.ecoenv.2011.10.001.

de Toffoli, A.L., Da Mata, K., Bisinoti, M.C., Moreira, A.B., 2015. Development, validation, and application of a method for the GC-MS analysis of fipronil and three of its degradation products in samples of water, soil, and sediment. J. Environ. Sci. Health B 50, 753-759. http://dx.doi.org/10.1080/03601234.2015.1058091.

Dornelles, M.F., Oliveira, G.T., 2014. Effect of atrazine, Glyphosate and Quinclorac on biochemical parameters, lipid peroxidation and survival in bullfrog tadpoles (Lithobates catesbeianus). Arch. Environ. Contam. Toxicol. 66, 415-429. http:// dx.doi.org/10.1007/s00244-013-9967-4.

Dornelles, M.F., Oliveira, G.T., 2016. Toxicity of atrazine, glyphosate, and quinclorac in bullfrog tadpoles exposed to concentrations below legal limits. Environ. Sci. Pollut. Res. Int. 23, 1610-1620. http://dx.doi.org/10.1007/s11356-015-5388-4.

Eaton, D., Bammler, T.K., 1999. Concise review of the glutathione S-transferases and their significance to toxicology. Toxicol. Sci. 49, 156-164. http://dx.doi.org/ 10.1093/toxsci/49.2.156.

Edwards, C.A., 1993. The impact of pesticides on the environment. In: Pimentel, D. Leman, H. (Eds.), The Pesticide Question: Environment, Economic and Ethics. Springer Verlag Science, New York, 13-46.

Frova, C., 2006. Glutathione transferases in the genomics era: new insights and perspectives. Biomol. Eng. 23, 149-169. http://dx.doi.org/10.1016/ j.bioeng.2006.05.020.

Glock, G.E., McLean, P., 1953. Further studies on the properties and assay of glucose 6phosphate dehydrogenase and 6-phosphogluconate dehydrogenase of rat liver. Biochem. J. 55, 400-408. http://dx.doi.org/10.1042/bj0550400.

Gosner, K.L., 1960. A simplified table for staging anuran ambryos and larvae with notes on identification. Herpetologica 16, 183-190.

Goto, S., Kawakatsu, M., Izumi, S., Urata, Y., Kageyama, K., Ihara, Y., Koji, T., Kondo, T., 2009. Glutathione S-transferase pi localizes in mitochondria and protects against oxidative stress. Free Radic. Biol. Med. 46, 1392-1403. http://dx.doi.org/10.1016/ j.freeradbiomed.2009.02.025.

Gunasekara, A., Troung, T., 2007, Environmental Fate of Fipronil. Report. Environmental Monitoring Branch, Department of Pesticide Regulation, California Environmental Protection Agency, Sacramento, CA.

Gustafson, D.I., 1989. Groundwater ubiquity score: a simple method for assessing pesticide leachability. Environ. Toxicol. Chem. 8, 339-357. http://dx.doi.org/ 10.1002 /etc. 5620080411.

Hoerger, C.C., Akhtman, Y., Martelletti, L., Rutler, R., Bonvin, F., Grange, A., Arey, J.S., Kohn, T., 2014. Spatial extent and ecotoxicological risk assessment of a micropollutant-contaminated wastewater plume in Lake Geneva. Aquat. Sci. 76, 7-19. http://dx.doi.org/10.1007/s00027-013-0315-6.

Katagi, T., 2004. Photodegradation of pesticides on plant and soil surfaces. Rev. Environ. Contam. Toxicol. 182, 1-195.

Keen, J.H., Habig, W.H., Jakoby, W.B., 1976. Mechanism for the several activities of the glutathione S-transferases. J. Biol. Chem. 251, 6183-6188.

Ki, Y.W., Lee, J.E., Park, J.H., Shin, I.C., Koh, H.C., 2012. Reactive oxygen species and mitogen-activated protein kinase induce apoptotic death of SH-SY5Y cells in response to fipronil. Toxicol. Lett. 211, 18-28. http://dx.doi.org/10.1016/ j.toxlet.2012.02.022.

Kletzien, R.F., Harris, P.K., Foellmi, L.A., 1994. Glucose-6-phosphate dehydrogenase: a "housekeeping" enzyme subject to tissue-specific regulation by hormones, nutrients, and oxidant stress. FASEB J. 8, 174-181.

LeNoir, J.S., McConnell, L.L., Fellers, G.M., Cahill, T.M., Seiber, J.N., 1999. Summertime transport of current-use pesticides from California's central valley to the Sierra Nevada Mountain range, USA. Environ. Toxicol. Chem. 18, 2715-2722. http:// dx.doi.org/10.1002/etc.5620181210.

Lushchak, V.I., 2011. Environmentally induced oxidative stress in aquatic animals. Aquat. Toxicol. 101, 13-30. http://dx.doi.org/10.1016/j.aquatox.2010.10.006.

Margarido, T.C., Felício, A.A., de Cerqueira Rossa-Feres, D., de Almeida, E.A., 2013. Biochemical biomarkers in Scinax fuscovarius tadpoles exposed to a commercial formulation of the pesticide fipronil. Mar. Environ. Res. 91, 61-67. http:// dx.doi.org/10.1016/j.marenvres.2013.02.001.

Maul, J.D., Brennan, A.A., Harwood, A.D., Lydy, M.J., 2008. Effect of sedimentassociated pyrethroids, fipronil, and metabolites on Chironomus tentans growth rate, body mass, condition index, immobilization, and survival. Environ. Toxicol. Chem. 27, 2582-2590. http://dx.doi.org/10.1897/08-185.1.

Möhler, H., Fritschy, J.M., Crestani, F., Hensch, T., Rudolph, U., 2004. Specific GABA(A) circuits in brain development and therapy. Biochem. Pharmacol. 68, 1685-1690. http://dx.doi.org/10.1016/j.bcp.2004.07.025.

Moreira, S.M., Moreira-Santos, M., Rendón-von Osten, J., da Silva, E.M., Ribeiro, R., Guilhermino, L., Soares, A.M.V.M., 2010. Ecotoxicological tools for the tropics: sublethal assays with fish to evaluate edge-of-field pesticide runoff toxicity. Ecotoxicol. Environ. Saf. 73, 893-899. http://dx.doi.org/10.1016/ j.ecoenv.2010.04.007.

Muneer, M., Theurich, J., Bahnemann, D., 1999. Formation of toxic intermediates upon the photocatalytic degradation of the pesticide diuron. Res. Chem. Intermed. 25, 667-683. http://dx.doi.org/10.1163/156856799×00220.

Ojha, A., Yaduvanshi, S.K., Srivastava, N., 2011. Effect of combined exposure of commonly used organophosphate pesticides on lipid peroxidation and antioxidant enzymes in rat tissues. Pestic. Biochem. Physiol. 99, 148-156. http://dx.doi.org/ 10.1016/j.pestbp.2010.11.011.

Peltzer, P.M., Lajmanovich, R.C., Attademo, A.M., Junges, C.M., Cabagna-Zenklusen, M.C., Repetti, M.R., Sigrist, M.E., Beldoménico, H., 2013. Effect of exposure to contaminated pond sediments on survival, development, and enzyme and blood biomarkers in veined treefrog (Trachycephalus typhonius) tadpoles. Ecotoxicol. Environ. Saf. 98, 142-151. http://dx.doi.org/10.1016/j.ecoenv.2013.09.010.

Peret, A.M., Oliveira, L.F., Bianchini, I., Seleghim, M.H., Peret, A.C., Mozeto, A.A., 2010 Dynamics of fipronil in oleo lagoon in Jataí Ecological Station, São Paulo-Brazil. Chemosphere 78, 1225-1229. http://dx.doi.org/10.1016/ j.chemosphere.2009.12.060.

Rand, G.M., Wells, P.G., McCarty, L.S., 1995. Introduction to aquatic toxicology. In: Rand, G.M. (Ed.), Fundamentals of Aquatic Toxicology: Effects, Environmental Fate, and Risk Assessment. Taylor \& Francis, Boca Raton, FL.

R Development Core Team, 2010. R: a language and environment for statistical computing. R Foundation for Statistical Computing. Vienna, Austria. Available at: 〈www.r-project.org〉.

Roques, B.B., Lacroix, M.Z., Puel, S., Gayrard, V., Picard-Hagen, N., Jouanin, I., Perdu, E., Martin, P.G., Viguié, C., 2012. CYP450-dependent biotransformation of the insecticide fipronil into fipronil sulfone can mediate fipronil-induced thyroid disruption in rats. Toxicol. Sci. 127, 29-41. http://dx.doi.org/10.1093/toxsci/ kfs094.

Sheehan, D., Meade, G., Foley, V.M., Dowd, C.A., 2001. Structure, function and evolution of glutathione transferases: implications for classification of non-mammalian members of an ancient enzyme superfamily. Biochem. J. 360, 1-16. http:// dx.doi.org/10.1042/bj3600001.

Slaninova, A., Smutna, M., Modra, H., Svobodova, Z., 2009. A review: oxidative stress in fish induced by pesticides. Neuro Endocrinol. Lett. 30 (Suppl. 1), S2-S12.

Sun, L., Jin, R., Peng, Z., Zhou, Q., Qian, H., Fu, Z., 2014. Effects of trilostane and fipronil on the reproductive axis in an early life stage of the Japanese medaka (Oryzias latipes). Ecotoxicology 23, 1044-1054. http://dx.doi.org/10.1007/s10646-0141248-0.

Tingle, C.C., Rother, J.A., Dewhurst, C.F., Lauer, S., King, W.J., 2003. Fipronil: environmental fate, ecotoxicology, and human health concerns. Rev. Environ. Contam. Toxicol. 176, 1-66. http://dx.doi.org/10.1007/978-1-4899-7283-5_1.

Tomanek, L., 2014. Proteomics to study adaptations in marine organisms to environmental stress. J. Proteom. 105, 92-106. http://dx.doi.org/10.1016/ j.jprot.2014.04.009.

Uchendu, C., Ambali, S.F., Ayo, J.O., 2012. The organophosphate, chlorpyrifos, oxidative stress and the role of some antioxidants: a review. Afr. J. Agric. Res. 7, 2720-2728. http://dx.doi.org/10.5897/ajar11.2510.

UNICA, 2015. União da industria da Cana-de-açucar (2012). Unicadata. 〈http://www. unicadata.com.br $\rangle$.

Woo, S., Yum, S., Kim, D., Park, H., 2009. Transcripts level responses in a marine medaka (Oryzias javanicus) exposed to organophosphorus pesticide. Comp. Biochem. Physiol. 149, 427-432. http://dx.doi.org/10.1016/j.cbpc.2008.10.100.

Yan, D., Jiang, X., Xu, S., Wang, L., Bian, Y., Yu, G., 2008. Quantitative structure-toxicity relationship study of lethal concentration to tadpole (Bufo vulgaris formosus) for organophosphorous pesticides. Chemosphere 71, 1809-1815. http://dx.doi.org/ 10.1016/j.chemosphere.2008.02.033. 